\title{
Os estudos culturais e a crítica literária no Brasil
}

Geraldo Ramos Pontes Jr. ${ }^{1}$

Como área de estudos acadêmicos voltada para uma diversidade de objetos e pouco específica na definição de cultura em que propõe fundar-se, os estudos culturais têm encontrado a um só tempo repulsa e adesão no âmbito dos estudos literários brasileiros nas duas últimas décadas. Repulsa, pelo descrédito de críticos preocupados com as particularidades do literário e a delimitação do campo do comparativismo como exclusivo da teoria (quase ciência) literária. Adesão, tanto pela flexibilidade que o campo propõe em relação a outros que requeiram rigor na construção de uma exegese dependente do uso conceitual quanto pela necessidade de revisão de uma teoria em crise diante da diversidade "heterodoxa", sem ser isso um pleonasmo, do conjunto de valores culturais no fim de um século bastante conturbado, valores encarnados inclusive na figura de autores cujas obras estão marcadas por grande descentramento cultural.

Tais fenômenos abriram rapidamente um espaço de debate aqui, no início dos anos 1990, paralelamente à já vigente tradição britânica e norte-americana. O terreno já se mostrara fértil, pois, em fins dos anos 1970, procurando rever nosso legado moderno, Silviano Santiago abriu perspectivas distintas das que se praticavam na crítica literária, através de reflexões que buscavam paradigmas não eurocêntricos, na releitura da noção de dependência cultural expressa pela escrita literária e, consequentemente, na revisão dos processos de apropriação da tradição ocidental, em um palimpsesto que assegurava uma lógica universal para a literatura aqui produzida. O conjunto de ensaios Uma literatura nos trópicos, reunidos em edição de 1978, aponta principalmente para a questão da escrita, mas já se detém em algumas outras questões da cultura brasileira, como a música popular. Quanto a esse último aspecto, duas décadas depois, ${ }^{2}$ balizando textos - ou livros - de já quase vinte anos passados, o autor ressalta a transição do legado marxista ou histórico para o olhar antropológico na academia que no fim dos anos

\footnotetext{
${ }^{1}$ Doutor em literatura brasileira e professor do Instituto de Letras da Universidade do Estado do Rio de Janeiro (UERJ), Rio de Janeiro, RJ, Brasil. E-mail: geraldo.pontes@uol.com.br

${ }^{2}$ Trata-se do texto A democratização no Brasil (1979-1981): cultura versus arte, primeiramente editado por Raul Antelo, em 1998, depois incluído em O cosmopolitismo do pobre (2008), edição utilizada aqui.
} 
1970 desierarquizava a literatura em relação a outras manifestações discursivas, ou seja, a guinada antropológica.

Por outro lado, alguns parâmetros de pensamento vigentes na universidade brasileira até os anos 1980 já haviam aberto discussões pertinentes à seara culturalista, entre concepções do discurso de Barthes, Foucault, Deleuze, Kristeva e de outros. Afastando-se dos modelos ortodoxos de estudos textuais, dos quais alguns desses autores eram tributários, seus avatares menos reducionistas dos esquemas herdados do estruturalismo contribuíam para se olhar a literatura na relação com a cultura, trazendo a abertura ao campo da crítica com relação ao pensamento teórico de origem formalista.

Historicamente falando, o campo dos Estudos Culturais identifica-se com a transformação no pensamento inglês do pós-guerra, onde fora iniciado graças a preocupações que demandavam um tratamento distinto do que se podia com a herança oitocentista das ciências sociais. Raymond Williams, Richard Hoggart e E. P. Thompson, principalmente, trouxeram contribuições com que os pesquisadores da New Left Review, como Stuart Hall e Paul Gilroy, reformularam o legado marxista a partir do pensamento de Gramsci. A preocupação em se ultrapassar o pressuposto marxista de base/superestrutura na abordagem de questões da classe trabalhadora, o questionamento sobre o mesmo para se pensar a posição social das mulheres operárias, e até a reflexão acerca da supressão do lazer na vida operária inglesa, levaram Hall (2003a) ${ }^{3}$ a identificar nos seus antecessores elementos fundamentais para a virada do campo, elegendo-os como representativos de um dos dois importantes paradigmas para seu nascimento. A partir daí, a corrente inglesa evidenciou-se no trabalho dos epígonos, com ensaios sobre raça, sexualidade, identidade, em direção ao domínio do sujeito como protagonista da cultura. Segundo Frederic Jameson, ${ }^{4}$ acontecimentos da década de 1960 haviam trazido mudanças de paradigmas na visão de conjunto. Tornaram-se destoantes da concepção "do que é historicamente dominante ou hegemônico" (Jameson, 1991, p. 82) e realçaram o espectro cultural. A transformação dos "nativos", ou "minorias, marginais e mulheres" do Primeiro Mundo, assim como descolonizados da África e da Ásia, em humanos (Jameson, 1991, p. 85),

\footnotetext{
${ }^{3}$ O texto "Cultural studies: two paradigms" foi inicialmente publicado em 1980.

${ }^{4}$ Texto incluído em um compêndio organizado por Heloísa Buarque de Hollanda sobre o pósmodernismo.
} 
que passavam a falar sem o intermediário de intelectuais e outros, evidenciou a emergência discursiva desses novos sujeitos fazendo desaparecer a categoria de classes sociais, abolindo a tradução de perspectivas marxistas clássicas para o entendimento das mudanças, o que exigiu maior reflexão sobre a revolução cultural decorrente. $\mathrm{O}$ tema, complexo, é longamente tratado pelo crítico. Mas paralelamente aos fatos por ele analisados, podemos estabelecer a pertinência dos Estudos Culturais na compreensão dos discursos de emancipação decorrente de seu esforço de revisão do legado marxista.

Em 1992, já considerando o legado dos estudos culturais, Hall refletia sobre problemas quanto ao que denominava a sua "fluência teórica [...] nos Estados Unidos". ${ }^{5}$ Vendo sua inserção ligada ali ao "dilúvio desconstrutivo (em oposição à virada desconstrutiva)" (Hall, 2003b, p. 215), perguntava-se se as relações entre poder e política, indissociáveis do enfoque em representações, seriam sempre passíveis de ser encaradas como questões discursivas, conforme a ilimitada possibilidade de se teorizar o poder, da raça ao gênero, da política à classe. Desconfiava de um certo descrédito acerca da "textualização esmagadora dos próprios discursos dos estudos culturais" pois se passava a constituir "o poder e a política como questões exclusivamente de textualidade e de linguagem". Preocupado com a apropriação dessa corrente pelos norte-americanos, que privavam de significação, conforme o uso, "o grosseiro exercício e as ligações do poder e da cultura", apontava para o perigo "na institucionalização dos estudos culturais no altamente rarefeito, enormemente elaborado e bem-financiado mundo profissional da vida acadêmica norte-americana" (Hall, 2003b, p. 216).

Esse ensaio foi reeditado em um compêndio em 1993, pela editora britânica Routledge, incluindo autores que não participaram da primeira edição. The cultural studies reader, apresentado por Simon During, reunia onze domínios para fundamentar o campo, que iam da teorização do método às políticas econômicas para a gestão da cultura, na qual se ponderavam o legado de Benjamin, textos norteadores de Adorno e Horkheimer, assim como Barthes; dos domínios de espaço e tempo, ensaios seminais sobre arquitetura, modernidade e pósmodernidade, assinados por Jameson, entre outros; de carnavalização e

\footnotetext{
${ }^{5} \mathrm{O}$ texto "Cultural studies and its theoretical legacies" foi publicado inicialmente em 1992 por Lawrence Grossberg et al. em seguida ao debate ocorrido naquele ano na Universidade americana de Urbana-Champaign.
} 
utopia ao lazer e música como entretenimentos (Bourdieu); dos domínios do nacional e do global, passando pelo pós-colonial (segundo Bhabha e Spivak), completando-se com temas como etnicidade, sexualidade e gênero (com um ensaio de Judith Butler, entre outros) até se chegar ao âmbito das dinâmicas pragmáticas, nas quais se elencavam textos sobre campos emergentes na ciência, a cibercultura, consumo e mercado; por fim, da relação entre a mídia e as esferas públicas à problematização da censura, nas sociedades totalitárias, e ao revés da democracia, no questionamento de seus limites no Ocidente.

Como se vê, o pós-estruturalismo francês teve sua inserção nesses debates. E revelou uma importância fundamental para Hall, que, ao distinguir as contribuições de Foucault e Barthes na compreensão do discurso, como categoria operacional para a cultura contemporânea, entendia essa corrente como o segundo paradigma do novo campo. A crítica brasileira gozava, portanto, da familiaridade com a corrente francesa ao interagir com as novas perspectivas pertinentes aos estudos culturais. Mas a relação da cultura com o espectro multidisciplinar não metódico desse saber trouxe alguns problemas de percurso, mormente no seu impacto estrutural sobre o meio acadêmico brasileiro, como esclarece a pesquisadora Rachel Lima (2000, 2009, 2010), em análise de consequências posteriores. Entre problemas e pressões em torno da reforma da própria estrutura acadêmica e "uma naturalização da ideia de crise nos discursos produzidos sobre a Literatura Comparada" (Lima, 2010, p. 27), a autora faz alguns balanços do impasse que chega a fragmentar as ações da Associação Brasileira de Literatura Comparada (ABRALIC) na gestão das divergências de tendências da crítica, dividida entre adeptos do "nomadismo da disciplina, como forma de seu vigor" e os "inconformados com a expansão de seu raio de ação e com a incorporação de teorias que desestabilizam os modelos interpretativos antes hegemônicos" (Lima, 2010, p. 27). Contudo, só poderemos nos deter aqui em alguns aspectos de divergências teóricas iniciais sobre a visão culturalista, conforme o que se presta este artigo.

Durante os anos 1980, a teorização sobre o discurso ${ }^{6}$ alcançou uma dimensão importante, evidenciando o processo de redemocratização no Brasil, em várias esferas. Ainda que a "o direito de falar com sua própria voz, por si mesmo" como expressão autêntica das novas demandas não

\footnotetext{
${ }^{6}$ Pense-se em estudos como Cultura e democracia: o discurso competente e outras falas, de Marilena Chaui, além das sucessivas traduções de autores do pós-estruturalismo aqui já referidos.
} 
"signifique forçosamente satisfazê-las" (Jameson, 1991, p. 90), o vulto do lema pós-estruturalista da "conquista do discurso" (Jameson, 1991, p. 90) na universidade incorpora inicialmente essa perspectiva, que torna o campo das humanidades interdisciplinar. Há que se notar, portanto, a maior relevância de questões emergentes atravessando e dialogando com a produção de um saber sobre a literatura de forma a aproximá-la da cultura, dos discursos que inserem as novas categorias sociais na cultura, sob o testemunho literário, e os desdobramentos que chegaram até os dias de hoje para os parâmetros investigativos.

Ora, paralelamente à atualização dessas perspectivas aos estudos literários no Brasil, uma parcela da crítica literária brasileira teve a reação imediata de ceticismo quanto ao antimétodo e a seu lugar entre nós. Entendia a interdisciplinaridade em outra perspectiva e considerava fundamental a independência requerida pela crítica literária em relação a outros campos de saber, sem se misturar a eles. A reação correspondeu à defesa de alguns teóricos, em coerência com suas trajetórias, a que se opuseram outros, não menos coerentes, com perspectivas interdisciplinares distintas.

Evidentemente, a delimitação teórica em prol da especialidade do campo e da posição de seus defensores com os debates de outras áreas visa a assegurar a primazia de critérios que lhe seriam favoráveis na hierarquia do conhecimento. Em outras palavras: "O embate entre as correntes da crítica que postulam a existência de uma teoria rigorosa, sistemática e os críticos culturais, responde pela necessidade de se manter o controle epistemológico em relação ao objeto de estudo" (Souza, 1998, p. 22).

A princípio, esse conhecimento específico organizaria os sentidos do seu objeto, de dentro para fora do campo, por mais que se assemelhe a um desnecessário ditame. Entre outros fatores importantes a ponderar hoje, decorrentes daí, está a consequência de se solidificar o campo como formador dos futuros profissionais de uma área de saber, suas aplicabilidades na sociedade, como no magistério de letras, no campo editorial, na área de tradução, entre outros. No entanto, vê-se desde sempre o contrário disso acontecer com grande aceitabilidade entre críticos, tradutores e professores universitários, como se a formação para o magistério escolar se dissociasse completamente da pesquisa universitária de letras, pela qual se interessariam com grande frequência profissionais 
originários de outros campos. ${ }^{7}$ De fato, produzir conhecimento e pesquisa sobre a literatura (e outras artes) nunca foi do exclusivo domínio da crítica literária (e dos demais campos artísticos) por aqui.

Do outro lado da moeda, a boa receptividade dos estudos culturais pode ter majoritariamente correspondido à aplicação de modelos interpretativos de distintos fenômenos de identidades, aproximando discussões literárias de modelos sociológicos da análise de obras, como já se fazia antes. Mas há novos problemas no percurso. Ainda que não mais seguindo a perspectiva marxista, na relação base/superestrutura, muito criticada por Stuart Hall (2003a), a vertente constata desgastes da "moda", pela necessidade de ultrapassar simples patamares de discussões essencialistas, entre outras. Com o alto grau de especialização das diferentes carreiras nas humanidades e na área de letras, as formações acadêmicas ainda são marcadas por currículos endógenos que dificultam o trânsito do discurso teórico ao se lançar mão de perspectivas de outras áreas. E, quando o trânsito se dá, sem estofo suficiente, produzem-se mecanismos muito próximos aos da aplicação de conceitos.

A diferenciação dos estudos literários em relação a outros domínios de saber que também se voltaram para o mesmo objeto foi defendida por críticos que procuraram demonstrar maior ou menor alcance das vertentes disciplinares nos estudos de obras, em confronto com concepções textuais de bases linguísticas, formalistas e semiológicas. Através dessas, o aspecto de representação da arte foi balizado pelo enfoque de particularidades da "obra do imaginário" de que se constitui um texto, diferenciando o discurso literário de outros saberes. Consequentemente, seria possível ao pesquisador postular o caráter estético capaz de aglutinar interesses mais abstratos de leitores e espectadores sobre a representação em questão como arte, chegando-se mais próximo ao campo da filosofia.

Se esse guardião da superioridade da crítica foi ou não um melhor definidor do domínio literário que o amplo e quase inefável conceito de cultura exaustivamente discutido por Stuart Hall (1980, 1992, 1997), no âmbito dos estudos culturais, mais vale pensar que nos estudos culturais a relação das obras com a "cultura" não se calca no estabelecimento de parâmetros hierárquicos. Ainda assim, o significado

\footnotetext{
${ }^{7}$ Até mesmo entre críticos de renome, com formação em ciências sociais, como Luiz Costa Lima e Antonio Candido, houve migração para a área de letras.
} 
desse produto do imaginário nunca deixou de ser do interesse de outros campos, que constituíram inclusive sentidos mediados pela arte para seus saberes, desde tempos remotos a tal debate (como a tragédia grega para a psicanálise freudiana).

O que teria sido interdisciplinar devia-se à pertinência de conceitos ou perspectivas que passaram por reformulação nas próprias áreas de saber de origem. Nas antigas reflexões a respeito no Brasil, mostrou-se a interdisciplinaridade como diálogos entre correntes. Foi assim que, enquanto durava e se prolongava a compreensão de textos literários pelos vieses codificados de seu pertencimento histórico e filológico a escolas ou a conjuntos nacionais histórica e culturalmente constituídos, servindo de modelo para literaturas que seriam seus troncos em novas nações, obras como Falência da crítica (1973), de Leyla Perrone-Moisés, ou Teoria da literatura em suas fontes (1975), de Luiz Costa Lima, ainda que voltadas para objetivos distintos, definiram perspectivas interdisciplinares na constituição do campo teórico da literatura. Da análise sociológica às críticas psicológica, temática, histórica (e, para Perrone-Moisés, a sua suposta superação pela crítica semiológica francesa), até o surgimento de questionamentos sobre a hierarquização do valor de leituras pela estética da recepção e do efeito (em Costa Lima), entre outras, esses críticos estabeleceram relações entre a interpretação literária e campos implícitos nessas vertentes e a preocupação de depurar os sentidos da literatura e contrabalançar suas noções formais a perspectivas de maior rigor, como a literariedade. Ambos os estudos propunham enxergar tanto limites de alcance quanto avanços de perspectivas para o entendimento da ficção, da poesia, na mediação de saberes que campos das distintas vertentes da crítica punham em diálogo com o texto.

Certamente convictos de que tais balizamentos salvaguardavam o lugar da crítica literária, duas décadas depois, no $5^{\circ}$ Congresso da ABRALIC, esses críticos se opuseram claramente ao campo dos estudos culturais. Atentos ao debate, Wander Melo Miranda e Eneida Maria de Souza travaram uma discussão a esse respeito no $\mathrm{n}^{\circ} 4$ da Revista de Literatura Comparada, posterior à publicação dos Anais do $5^{\circ}$ Congresso. Preparando argumentos para a edição seguinte do evento, e como reação às posturas dos dois críticos referidos, procuraram mostrar que uma dinâmica distinta se via surgir nas posições que assumiam diferentes críticos, buscando-se a repercussão da crise da teoria lá fora, 
com balanços de novos desafios. Apontavam para a redefinição do papel da crítica na discussão da interdisciplinaridade e no que diz respeito à concepção da produção local como um conjunto uno e indivisível (Miranda, 1998a). Afora isso, no evento de 1998, as distintas interfaces dos estudos culturais foram abordadas em mesas que trataram de assuntos que já se distanciavam completamente daquela crítica em sua indivisibilidade da abordagem da literatura nacional.

Ora, qual a diferença decorrente de recortes interpretativos dos estudos culturais e das vertentes da crítica que constituíram até há algum tempo (ou que se incluem ainda hoje em parte do programa de teoria da literatura nos cursos de graduação) uma amostragem do diálogo entre disciplinas "externas" e o saber hierarquizado pela "crítica" sobre o literário? Algumas preocupações nesse campo foram articuladas por Eneida Maria de Souza. Ao considerar que patamares tradicionais de entendimento do literário, como a "condição da obra esteticamente concebida" e a valorização de "critérios de literariedade", deviam dar lugar à interpretação da literatura como "produto capaz de suscitar questões de ordem teórica ou de problematizar temas de interesse atual, sem se restringir a um público específico" (Souza, 1998, 20), a autora demonstrava o impasse dos teóricos com a "crise" por que passava a disciplina, atingida por uma "crescente diluição das fronteiras disciplinares e dos objetos específicos de estudo, provoca(ndo) discussões mais abrangentes na área das humanidades, abalada pela abertura epistemológica e pelo enfraquecimento de territórios" (Souza, 1998, p. 20).

Em um balanço histórico, Souza aponta nesse texto para o fim da visão historicista, psicológica e biográfica do literário como ganho das heranças formalista e estruturalista, em sua base linguística, e demonstra, no avatar do estruturalismo em seu "após", com Deleuze e Guattari, Derrida e Foucault, a provocação do temor em críticos que viam nos novos autores o perigo da "diluição do objeto de análise" (Souza, 1998, p. 21). Ao defender a ideia da interdisciplinaridade como "novo gênero", opondo-se à resistência de Kwame Anthony Appiah aos estudos culturais, e ao afirmar que autores como Antoine Compagnon, Luiz Costa Lima, Leyla Perrone-Moisés e Siegfried. J. Schmidt (este último através de pesquisa de Heidrun Kriegger Olinto) seriam partidários do controle do objeto de estudos, Souza mostra que suas opiniões revelariam uma "censura ao ecletismo" e iriam de encontro ao “caráter regulador da crítica cultural, ao considerar elitista a preferência 
do estudioso por escritores consagrados e tradicionalmente aceitos pela comunidade acadêmica" (Souza, 1998, p. 22).

Em seguida, ressalta a mudança, identificada pelos conservadores, do poder analítico à generalização, avaliando que "reconhecer a tradição como força e não como modelo seria uma das formas de melhor lidar com a proposta desconstrutora de Jacques Derrida" (Souza, 1998, p. 24). Reportando-se ao interesse desse trabalho como ponderação das reações dos críticos que se manifestaram no evento da ABRALIC, Souza comenta a defesa de Luiz Costa Lima em buscar uma homogeneidade interna do objeto, a que se opõe afirmando "a necessidade de serem consideradas posições teóricas que funcionem como articuladoras das proposições de análise como elementos dignos de operar o distanciamento crítico" (Souza, 1998, p. 25).

Do trabalho de Heidrun Olinto, a respeito da reação de Schmidt à falta de uma herança filosófica no espaço acadêmico norte-americano, Souza ressalta a resposta do teórico, através de "teorias sistêmicas complexas", à "frouxidão epistemológica das teorias pós-modernas" (Souza, 1998, p. 26). Apresenta ainda a defesa de Compagnon, com sua obra $O$ demônio da teoria, ao desempenho do papel de combate ao senso comum pela teoria, ao mesmo tempo que reconhece o questionamento da verdadeira teoria a si própria, colocando em causa seu próprio discurso (Souza, 1998, p. 25). A propósito, a autora cita a afirmação de Compagnon de que "a perplexidade é a única moral literária" (Souza, 1998, p. 27), o que nos levaria a fechar esse pensamento, naquele balanço de fim de século, lembrando que a crítica tem em seu étimo o termo crise e, assim sendo, justifica-se sempre o debate acerca de seus parâmetros.

Ressaltando-se das preocupações de Eneida Maria de Souza o fato de que a modificação por que passava a interdisciplinaridade dava-se acima do enfoque dos usos, erros e acertos da perspectiva de tratamento do literário, percebe-se um descentramento de modelos interpretativos articulados por uma teoria. A interface da literatura com essas áreas de conhecimento apontava então para a necessidade da mediação das discussões do presente entre leitor e obra, aumentando-se as lentes sobre a perspectiva do sujeito no coletivo, a literatura como intérprete de uma outra condição humana, por assim dizer, na confluência de campos de saber, traduzida pelo sentido que passa a ter a categoria do discurso literário. O literário como discurso e a posição do escritor se 
complementariam então na avaliação de outros aspectos enriquecedores para o repertório da crítica.

$\mathrm{O} 6^{\circ}$ Congresso ABRALIC, com o tema "Literatura comparada = estudos culturais?", aguçou a polêmica. Wander Miranda acrescentava ponderações novas, preocupado com a ausência de reflexão sobre o próprio objeto de estudos que se disputava em nome de campos de saber. Mostrava que, de uma suposta perspectiva externa ao objeto, ou seja, das ciências que dele se apoderaram, deveria se pautar em uma questão talvez interna a ele, ou seja, a sua forma de refletir a cultura em valores, pois:

A essa nova forma de articulação segue-se a noção de arte como um sistema cultural em que a diferença se apresenta como um processo de significação no qual, na contemporaneidade, se afirmam campos de força distintos e distintos critérios de avaliação. Ao valor enquanto horizonte consensual, a ser atingido pelo juízo crítico fundado na aludida demanda de universalidade e totalização, contrapõe-se a relação como valor, o que reforça o componente comparativista dos estudos que visam à abordagem do objeto cultural, artístico ou literário hoje em dia. Daí a emergência de um entre-lugar discursivo como possibilidade de redefinição do valor da literatura e de reformulação do comparativismo como estratégia de resistência à uniformização globalizante (Miranda, 1998b, s.p.).

O campo teórico da tradição não daria conta da negociação de valores que advém do próprio objeto que disputa e se mantém fechado a parâmetros de julgamento que se formaram no próprio surgimento e história dessas disciplinas. Seria necessário, portanto, redefinir os caminhos do comparativismo, respeitando-se o fato de que:

A problematização dos limites disciplinares que a literatura comparada passa a enfrentar, acirrada pela disseminação e fragmentação do saber na pós-modernidade, pauta-se pela desconstrução do parâmetro de referência que a institucionalizou como disciplina: a centralidade das literaturas metropolitanas e a escala hierárquica que introduzem na relação comparatista. Diante da situação engendrada pela radicalização da crítica ao eurocentrismo histórico da disciplina, trata-se de chamar a atenção para o fato de que objetos literários diferenciados são formas liminares de representação social e de redimensionamento de práticas políticas, considerando-se a heterogeneidade que 
constitui essas formas e que só podem ser bem percebidas quando se cruzam as fronteiras de um território - disciplinar ou cultural. Esse ponto de cruzamento ou intersecção revela que as identidades são sempre identidades virtuais, no sentido de que se situam "entre o não ser e o ser outro", para retomar a conhecida formulação de Paulo Emílio Salles Gomes, não mais como um estigma e sim como a própria condição de possibilidade de toda e qualquer cultura (Miranda, 1998b, s.p.).

Por seu turno, a pesquisadora Eneida Leal Cunha procurou ponderar a real adequação para as discussões nacionais em relação aos debates de campos disciplinares que se trazia de fora, chamando a atenção para a proposição intelectual em relação ao seu papel diante dos próprios campos interdisciplinares que escolhe para estudar:

Muito do que se tem produzido na nossa peculiar Literatura Comparada submete-se explicitamente ao rótulo de Estudos Culturais, mas isso é muito pouco para assegurar-lhes uma função pós-disciplinar. Para tanto, além de transformar a insatisfação em eficácia desconstrutora da ordem disciplinar instituída - através do trabalho de sua decomposição, reavaliação, transvaloração e transformação - é preciso, parece-me, que simultaneamente se extrapolem também os limites da própria questão disciplinar e da atividade intelectual tal qual se definiram nas academias modernas, lúcidas mas confinadas ao diálogo entre pares. É preciso também violar essas fronteiras, e buscar estar à altura de alianças eficazes - participação, contiguidade - com outros grupos sociais, com aqueles - aquilo - que muitas vezes elegemos, à distância, como nossos objetos de interesse intelectual. Esses seriam ímpetos pós-disciplinares fortes (Cunha, 1998, s.p.).

Todo esse ponto de partida da segunda metade dos anos 1990, resgatado pela leitura de Eurídice Figueiredo (2010), no balanço da relatividade dos dois lados da discussão, dá-nos a referência para revermos o momento mais tenso dessa discussão em âmbito associativo, no qual se trava a luta por posições e sua legitimação. Quanto ao balanço dessa pesquisadora, lê-se que:

A Literatura Comparada no Brasil pode tirar partido das contribuições que os Estudos Culturais e pós-coloniais proporcionaram, sobretudo nas pesquisas sobre as questões 
identitárias, nacionais e transnacionais [...]. Como um pensamento se inscreve na história de cada país, é preciso ter o cuidado especial de, ao usar um conceito surgido em outro espaço de enunciação, refazer todo seu percurso a fim de não homogeneizá-lo, eliminando as nuanças que constituem a riqueza e a produtividade que ele tinha em seu surgimento. As literaturas e as culturas dos diferentes países da América apresentam situações bastante distintas, com alguns elementos de história comuns, constituindo um objeto de reflexão que deve mobilizar os esforços de grupos de pesquisa, na tentativa de se incrementar os estudos do comparativismo interamericano, diminuindo assim o desconhecimento recíproco entre nós (Figueiredo, 2010, p. 20).

Por sinal, Eurídice Figueiredo ainda ressalta que os departamentos de letras norte-americanos foram modernizados pela junção de campos como os estudos latino-americanos e os estudos culturais britânicos. Mas sobre o entendimento de que o ensaio latino-americano acerca das culturas nacionais surgidas dos processos de miscigenação colonial teria um estatuto prévio de estudos culturais, tanto que assim absorvidos na denominação dos departamentos de estudos norte-americanos, talvez fosse preciso ressaltar que o enfoque do sujeito em alguns dos grandes temas dos estudos culturais muda consubstancialmente.

Os conceitos latino-americanos que a autora elencará em um compêndio (Figueiredo e Noronha, 2005) 8 se originam majoritariamente de contextos de emancipação e reorganização territorial pós-colonial; redefinem autoimagens exóticas que se procura substituir por discursos baseados em uma quebra hierárquica de valores, não se aplicando apenas a mudanças culturais permanentes; falam de questões coletivas e globais na perspectiva de formações nacionais, da consolidação de identidades em quadros mais abrangentes. São discussões pertinentes a minorias, uma vez que o leque ampliado pela corrente dos estudos culturais britânicos e norte-americanos encerra conceitos de fragmentos no todo, na perspectiva de questionar a legitimidade de identidades previamente estabelecidas, nas quais a cultura espelha um patamar nacional.

No entanto, voltando aos norte-americanos, e no que diz respeito a discussões de raça, há problemas que foram tratados pelo olhar de fora. Gilroy (2001) aponta para erros na cisão proposta pela revista

\footnotetext{
${ }^{8}$ Interessante apanhado, em edição de seu trabalho junto aos integrantes de um grupo de pesquisa, entre outros autores.
} 
Afrocentricity em relação ao passado, como o de querer fundar a negritude com o ofuscamento da memória do tráfico negreiro. Dessa forma, identifica aí afirmações tautológicas nocivas aos parâmetros identitários e que tomam o lugar da reflexão crítica. $\mathrm{O}$ autor inglês entende que a reflexão sobre a memória da colonização e da escravidão mantém a visão dialética para se caminhar em direção a uma história do Atlântico negro que seja a de uma prática cultural entre nações e continentes, não encerradas em um continente ou espaço e constituídas através da diversidade. Como no enfoque de transculturação de Ortiz (1963) e em sua releitura por Mary Louise Pratt (1992), o ensaio latinoamericano não se aplicava tanto a configurações subjetivas no seio de um coletivo, nem mesmo no escopo de minorias. A razão de se interpretar o então novo atravessava pela perspectiva hegemônica local - a se pensar, além da transculturação, para Ortiz, em mestiçagem, para Gilberto Freyre, antropofagia para Oswald de Andrade etc. Ainda assim, esses estudos propuseram princípios pertinentes aos estudos culturais, como na perspectiva centro versus periferia, entre outros.

Mas, tanto quanto os autores que realçaram o valor dos estudos culturais, Figueiredo se posiciona em favor de distanciamento e relativização acerca da recepção dessa área do saber e da função da crítica nos parâmetros de interpretação e pesquisa literária diante de um mundo que se transforma. Esses pesquisadores enfocaram problemas de diversa ordem que respondem à fundamentada dúvida de teóricos do porte de Antoine Compagnon sobre os limites da teoria no fim do milênio - e ao cabo de um século, aproximadamente -, assim como ao centramento do ensaio sobre a literatura brasileira na perspectiva de um sistema culturalmente fechado.

Ponderando hoje esse recente texto de Figueiredo, na perspectiva de sua remissão a duas décadas de discussão, pode-se ver com clareza o efeito dos próprios fenômenos que puderam influenciar a crítica desde o próprio campo literário, em uma ampla perspectiva da cultura. No que diz respeito ao hemisfério Norte, onde alguns autores passaram a viver, como consequência de todo tipo de exílio ou de uma condição do entredois pós-colonial, a escrita traduziu essas situações, e a maior visibilidade acerca da circulação de obras literárias no mundo decorrente tornou patente o descentramento cultural de certos campos. Do exílio político ao autoexílio de culturas de origem, configuradas em nova geopolítica após os processos da descolonização, a escrita rompeu 
o parâmetro inicial do campo da literatura comparada. Graças à consagração e premiação desses autores originários de contextos póscoloniais das diásporas africana, asiática, caribenha, entre outros, inclusive na condição de ensaístas, ${ }^{9}$ as discussões acadêmicas diminuíram a primazia do enfoque nas literaturas nacionais, cujos limites já se haviam demonstrado no movimento de autoafirmação e emancipação de inspiração romântica, em um primeiro momento, e moderna, em outro, desfazendo parâmetros exóticos de congelamento de sentidos e abrindo a pauta para horizontes distintos que levavam até a incluir na perspectiva das literaturas nacionais exemplos não canônicos e comprovadores de uma diversidade capaz de dissensões (como o conceito de literaturas menores advindo da leitura deleuziana da obra de Kafka, judeu tcheco escrevendo em alemão, em tempos do Império Austro-Húngaro).

A condição do sujeito expressa pela escrita na contemporaneidade exigiu abordagens distintas. A noção de campos de línguas literárias que reúnem autores francófonos, anglófonos, lusófonos, entre outros casos, nas quais se abrem perspectivas comparativas atualizadas pela renúncia à ideia de hegemonia, exemplifica-se por aquilo que Rushdie chamou de "homens traduzidos". ${ }^{10}$ A dimensão subjetiva no coletivo estava aí patente, criando um olhar enviesado ao conjunto nacional e a diversos enfoques culturalmente monológicos, ratificando a leitura deleuziana acerca de Kafka em sua relação de escritor de uma cultura expressa na língua de outra, hegemônica. Na contemporaneidade, muito depois das transformações territoriais que sucederam à época de Kafka e das questões as mais variadas de raça e identidade daí decorrentes, acompanha o fenômeno a própria questão histórico-política das diásporas de povos do hemisfério Sul para o Norte e lê-se, na obra de alguns desses escritores, a voz de uma coletividade assim

\footnotetext{
${ }^{9}$ Afora a importância que vieram a ter na universidade inglesa o jamaicano Stuart Hall ou, nos Estados Unidos, o palestino Edward Said e os hindus Homi K. Bhabha e Gayatri Spivak, a universidade francesa, entre outras, já acolhia um certo número de migrantes originários do leste europeu, entre os quais dois expressivos atuantes na vertente estruturalista e pós-estruturalista da crítica, o búlgaro Tzvetan Todorov e a romena Julia Kristeva.

${ }^{10}$ Esse termo foi citado no texto Manifeste pour une littérature-monde en français, publicado no jornal Le monde, do qual foram signatários 44 autores originários de todo o mundo, em 17/3/2007, preconizando o fim da francofonia - como termo representativo de expressões pós-coloniais que ainda se oporiam a um império, e o nascimento de uma "literatura-mundo" em francês. Pelo termo de Rushdie, os autores buscavam a equivalência do status dos escritores de língua inglesa, que não pertenciam a um rótulo.
} 
(re)constituída. Os "homens traduzidos" configuram-se em um entrelugar de culturas e línguas, tornando frágeis as noções de pertencimento e identidade nacional, repassando a limpo relações assimétricas de poder que assolam seus países de origem e que vieram da arbitrariedade da colonização, entre outros processos. Tocam frequentemente, através desses dois aspectos, na questão racial e impactam com suas obras a compreensão histórica que se tinha do século que estava em vias de terminar.

O entendimento do "multiculturalismo" revelou-se necessário na miscigenação progressiva das culturas da Europa. A literatura, diante de uma série de problemas como forma de falar ao coletivo, decifra as mudanças e tantos outros discursos, ora pondo-os em cheque, ora ratificando-os nos limites de sua existência como discurso autônomo. Entre alguns deles, como o embate do fundamentalismo dos aiatolás iranianos com a obra de um autor, o anglo-hindu Salman Rushdie, radicalizado no lançamento de uma punição contra a pessoa do escritor por detratores de uma moral que lhes escapa, não seria a escrita exemplar do retorno da contundência da palavra capaz de desvelar um fantasma? O totalitarismo político de que o Ocidente parecia ter se distanciado historicamente, logo após o recém-derrubado muro de Berlim, e que, ao contrário, voltaria a lhe trazer grandes pesadelos, recolocava a literatura no centro de atenções e movia novos debates, reeditando alguns antigos.

É justamente na escrita de autores descentrados que se percebe o debate entre literatura e transformações sociais, assim como o desenvolvimento de ensaios problematizando a questão social pelo viés da inserção da literatura daí emergente no horizonte cultural. Isso resultou em um interesse para os debates da crítica por aqui, como podemos ler no texto de Heidrun Olinto:

As novas conexões transculturais não só modificaram as condições de produção e recepção da literatura ficcional, mas como diria Dietrich Hart "desde os anos 80 a lista de autores agraciados com o prêmio Nobel, pode ser lida como uma lição de neogeografia mundial". Os produtores dessas novas literaturas não buscam inspiração e interesse apenas em culturas nacionais; ao contrário, eles transitam, à vontade, nos cenários da world fiction, entre as culturas, na qualidade de eternos apátridas, ocupando não-lugares ou vivendo nos imaginary homelands 
celebrados por Salman Rushdie, escritor anglófono nascido na Índia (Olinto, 1998, s.p.).

O dilema se intensifica mais precisamente na Europa, mas tem seus desdobramentos na América do Norte como um todo. Ora, traçar um quadro como o precedente corresponderia a fazer história ou crítica literária? A teoria está em crise, diriam alguns ensaístas de ponta, de forma que se escusaria, aqui, apoiado neles, ter que responder. Ainda buscando construir essa resposta, líamos no mesmo texto de Heidrun Olinto:

Certamente existem outros motivos para estimular reformulações urgentes nos quadros teóricos de uma Kulturwissenschaft (ciência da cultura). Enquanto as filologias buscam, via de regra, os seus objetos de investigação no conjunto de textos literários existentes, as ciências da cultura, em princípio, não dispõem necessariamente de objetos e questionamentos próprios em seu espaço disciplinar que não pudessem ser tematizados, também, pelas diferentes filologias, ciências sociais ou pela história. Elas, antes, se distinguem em sua qualidade de e no papel de formas de moderação, de meios de compreensão e de uma espécie de "arte do multiperspectivismo". Elas distinguem-se, ainda, por sua aptidão em estabelecer diálogo entre estratégias, práticas e resultados altamente heterogêneos, especializados e sobretudo intransparentes para outras ciências; por sua habilidade em sinalizar de forma mais visível certas semelhanças estruturais, em atenuar fronteiras disciplinares e em desenvolver uma rede de relações, comparações, distinções, trocas e contextualizações. E é neste sentido que a Kulturwissenschaft não pode, nem deveria, ocupar o lugar de uma ciência específica de matriz particular, mas antes operar como espécie de instância metarreflexiva, um papel tradicionalmente atribuído à filosofia.

Mas por outro lado, defende-se também uma ideia quase contrária, no sentido da existência de um repertório próprio de problemas, métodos e objetos materiais para as ciências da cultura o que legitimaria a sua ocupação de um território além, entre ou acima das ciências do espírito tradicionais. Esse tipo de autocompreensão das ciências da cultura aproximaria o tipo de sua investigação de certos interesses da antropologia histórica, por exemplo, da cultura da mídia e da etnologia (Olinto, 1998, s.p.). 
Assim, entre diferentes esferas, o lugar da interdisciplinaridade se refaz na própria redistribuição de papéis das ciências e seu valor para a crítica literária. Ainda assim, a literatura, tornando-se significativa na observação de uma realidade que procura não somente criticar mas também testemunhar e que lhe seria tão mais arrebatadora quanto capaz de lhe trazer novos repertórios, revitaliza sua relação com o público leitor. Com um novo perfil de engajamento ou de posicionamento e ainda que conjugado a interesses mercadológicos, o papel da literatura acirrou-se na discussão de questões identitárias, de gênero e orientação sexual, seguindo o espaço aberto ao discurso dos movimentos sociais nesses campos, ou mesmo iniciado por discussões teóricas do pós-estruturalismo. Muitos desses temas foram abordados nos estudos literários brasileiros. Mais recentemente, nova relação com o conceito de periferia, através da escrita, se estabelece na observação da realidade social, e não na posição orbital à hegemonia do Ocidente: autores das favelas, classificados por diferentes rótulos como literatura marginal ou de periferia, que produzem um intertexto com a cultura do hip-hop, do rap, entre outros, conforme se lê no estudo recente de Paulo Roberto Tonani do Patrocínio (2013), entre outros.

Ora, diante desse quadro e da sua interculturalidade, como tratar da questão do juízo de valor que garantiu à disciplina da crítica, com a noção de uma textualidade literária, o conceito de literariedade? O atual contexto inverte a fórmula de Jean Ricardou (1971), a da "aventura de uma escritura", com que o autor procurou dar conta da exacerbação da "emancipação" dos modernos, mas hoje se observa o retorno da representação com a encenação de novos discursos, a discussão da realidade e, por fim, o retorno às "escrituras de novas aventuras"?

É certo que se institui novo debate em torno da necessidade de a literatura representar os novos dilemas do mundo, sem se perder o interesse pela obra literária enquanto produto de um campo autônomo, autorregulado através de seus próprios parâmetros - o que é matéria para outra discussão dos problemas aqui apresentados -, sem se voltar apenas e tão somente à realidade extraliterária, a um movimento de representação do real, social ou de enunciação do mundo. Não é possível afirmar que isso fundou uma interdisciplinaridade nada criteriosa, imputada à crítica que envereda pelos estudos culturais, na emergência de temas contemporâneos por que passeiam seus especialistas em gênero, etnia, sexualidade, entre outros. Das mudanças 
nos estudos literários em que se intensificou o interesse por todo esse debate, assim como sobre o repensar as esferas do nacional e do global, viu-se a reconfiguração de vários sustentáculos do comparativismo.

\section{Referências}

CHAUI, Marilena (1981). Cultura e democracia: o discurso competente e outras falas. São Paulo: Moderna.

COMPAGNON, Antoine (2012). O demônio da teoria. Belo Horizonte: Editora UFMG. CUNHA, Eneida Leal (1998). Literatura comparada e estudos culturais: ímpetos pós-disciplinares. In: CONGRESSO DA ABRALIC, 6. Anais... Florianópolis: NELIC. (CD-ROM.)

DURING, Simon (1993). The cultural studies reader. London: Routledge.

FIGUEIREDO, Euridice (2010). Representações de etnicidade: perspectivas interamericanas de literatura e cultura. Rio de Janeiro: 7Letras.

FIGUEIREDO, Euridice; Noronha, Jovita (2005). Conceitos de literatura e cultura. Niterói: Editora UFF.

GILROY, Paul (2001). O Atlântico negro: modernidade e dupla consciência. Tradução de Cid Knipel Moreira. São Paulo: 34.

HALL, Stuart (1980). Cultural studies: two paradigms. Media, Culture and Society, n. 2, p. 57-72.

HALL, Stuart (1992). Cultural studies and its theoretical legacies. In: GROSSBERG, Lawrence et al. (Orgs.). Cultural studies. New York: Routledge.

HALL, Stuart (1997). The centrality of culture: notes on the cultural revolutions of our time. In: KENNETH, Thompson. Media and cultural regulation. London: Open University and Sage.

HALL, Stuart (2003a). Estudos culturais: dois paradigmas. In: HALL, Stuart. Da diáspora: identidades e mediações culturais. Organização de Liv Sovik. Tradução de Adelaine La Guardia Resende et al. Belo Horizonte: Editora UFMG.

HALL, Stuart (2003b). Estudos culturais e seu legado teórico. In: HALL, Stuart. Da diáspora: identidades e mediações culturais. Organização de Liv Sovik. Tradução de Adelaine La Guardia Resende et al. Belo Horizonte: Editora UFMG. 
JAMESON, Frederic (1991). Periodizando os sessenta. In: HOLLANDA, Heloísa Buarque de (Org.). Pós-modernismo e política. Tradução de César Brites e Maria Luiza Borges. Rio de Janeiro: Rocco.

LIMA, Luiz Costa (1975). Teoria da literatura em suas fontes. Rio de Janeiro: Francisco Alves.

LIMA, Rachel Esteves (2000). Ainda a tradição do impasse. Alea, v. 2, n. 1, p. 131-139.

LIMA, Rachel Esteves (2009). Os estudos culturais e a crise da universidade moderna. Caderno de Estudos Culturais, Campo Grande, v. 1, p. 63-72.

LIMA, Rachel Esteves (2010). A resistência à empiria. Aletria, v. 20, n. 1, p. 25-33, jan./abr.

MIRANDA, Wander M. (1998a). Projeções de um debate. Revista Brasileira de Literatura Comparada, Florianópolis, n. 4, p. 11-17.

MIRANDA, Wander M. (1998b). Comparativismo literário e valor cultural. In: CONGRESSO DA ABRALIC, 6. Anais... Florianópolis: NELIC. (CD-ROM.)

PERRONE-MOISÉS, Leyla. Falência da crítica. São Paulo: Perspectiva, 1973.

OLINTO, Heidrun K. (1998). De que estamos falando quando falamos de literatura e cultura? In: CONGRESSO DA ABRALIC, 6. Anais... Florianópolis: NELIC. (CD-Rom.)

ORTIZ, Fernando (1963). Contrapunteo cubano del tabaco y del azúcar. La Habana: Universidad Central de las Villas.

PATROCÍNIO, Paulo Roberto Tonani do (2013). Escritos à margem: a presença de autores de periferia na cena literária brasileira. Rio de Janeiro: 7Letras.

PRATT, Mary Louise (1992). Imperial eyes: studies in travel writing and transculturation. London: Routledge.

RICARDOU, Jean (1971). Pour une théorie du nouveau roman. Paris: Seuil.

SANTIAGO, Silviano (1978). Uma literatura nos trópicos. São Paulo: Perspectiva.

SANTIAGO, Silviano (2008). O cosmopolitismo do pobre. Belo Horizonte: Editora UFMG.

SOUZA, Eneida Maria de (1998). A teoria em crise. Revista Brasileira de Literatura Comparada, Florianópolis, n. 4, p. 19-29.

Recebido em junho de 2014.

Aprovado em outubro de 2014. 


\section{resumo/abstract}

\section{Os estudos culturais e a crítica literária no Brasil}

Geraldo Ramos Pontes Jr.

Duas décadas após os primeiros debates acirrados sobre a corrente dos estudos culturais no campo do comparativismo literário no Brasil, pode-se fazer um balanço positivo das reflexões decorrentes como necessária postura de abertura em relação ao objeto da crítica, as mudanças no campo interdisciplinar da teoria literária e da literatura comparada e as perspectivas absorvidas por teóricos brasileiros que reagiram à repulsa inicial à corrente em questão.

Palavras-chave: crítica literária brasileira, estudos culturais, literatura comparada, teoria literária.

\section{Cultural studies and literary criticism in Brazil}

Geraldo Ramos Pontes Jr.

Two decades passed after the first intense discussions on the meaning of cultural studies for the comparativism as a literary field in Brasil, this article proposes an examination that leads to positive results on the reflexions about the necessity of new positions towards the critic subject, changes on the interdisciplinary fields of comparative literature and literary theory, as well as the incorporated perspectives by Brazilian specialists that criticized the initial refusal to those studies.

Keywords: Brazilian literary criticism, cultural studies, comparative literature, literary theory. 